\title{
Research on the Difficulties and Countermeasures of the Development of China's Industrial New City
}

\author{
Xuejia $\mathrm{Li}^{1}$, Hongjian $\mathrm{Yu}^{2}$ \\ Hangzhou Normal University Alibaba Business School \\ 2405514507@qq.com \\ Xuejia Li
}

Keywords: industrial new city, development, dilemma, countermeasure

\begin{abstract}
The industrial new city is the product of the upgrading of the industrial park, which is composed of industry, population and city., population and city. In the context of China's new urbanization, industrial new cities are generally dominated by government investment. With the increase of population in various regions and the lack of capital technology and reasonable planning and operation, a series of problems have emerged in the development of China's industrial new cities. Based on theoretical analysis and practical research, this paper analyzes the dilemma of the development of China's industrial new city, and puts forward the countermeasures and suggestions for the development of industrial new city.
\end{abstract}

\section{中国产业新城发展的困境及对策研究}

\author{
李习佳 ${ }^{1}$, 余红剑 ${ }^{2}$ \\ 杭州师范大学 阿里巴巴商学院 \\ 2405514507@qq.com \\ 李习佳
}

关键词: 产业新城, 发展, 困境, 对策

摘 要: 产业新城是产业园区升级后的产物, 由产业, 人口, 城市组成。在我国新型城镇化背 景下，产业新城一般由政府投资主导，随着各地区人口的增加，以及缺乏资金技术和合理的 规划运营, 使得我国产业新城在发展中出现了一系列的问题。本文在理论分析和实践研究的 基础上，分析了我国产业新城发展的困境，并提出了产业新城发展的对策和建议。

\section{1. 引言}

产业新城相对来说是一个崭新的概念，随着城市的演变发展和新型城镇化的不断推进， 产业新城作为此过程的产物营运而生。产业对一个城市发展的作用是不可估量的, 在很大程 度上决定了一座城市的经济、政治和文化的发展, 因此打造以产业为主的新城, 成为城市发 展的新趋势, 展示了强大的生命力和活力。国内外许多优秀的产业新城正蓬勃发展, 这些产 业新城实现了产业功能与城市功能的相融合, 城市功能合理, 生态环境良好, 产业高度聚集, 就业人口与居住人口结构相适应。也有一些发展处于困境的新城, 产业规划不合理、招商没 有突破、融资难、没有做到产城融合等问题。

产业是一座城市发展的动力, 城市是产业发展的载体, 产业和城市相互依存, 共同发展。 改革开放以来, 我国经济得到快速发展, 新型城镇化也不断加快, 在这样的背景下, 人口急 剧增加，城市规模不断扩大，由此在城市外围出现了大量的开发区和工业区，人口也不断向 
这些集聚区迁移。这就会带来一系列的问题，资源浪费，就业压力大，环境破坏等。随着产 业新城数量的增加和规模的扩大, 一些发展问题也会随之显现, 最主要的就是产业发展和城 市建设脱离，产城不融合，有产无城或有城无产。

国内许多学者对产业新城的内涵和特征以及产业新城的未来发展趋势做了研究, 但是没 有系统地分析我国产业新城发展的一些问题, 本文通过理论分析和实践调查, 研究了我国产 业新城发展过程中面临的困境, 并提供相关建议和对策, 以此促进我国产业新城更好的发展。

\section{2. 产业新城}

产业新城是在新型城镇化建设背景下，在城市的外围建设一定密集的产业园区，这类密 集的园区在完善城市功能的同时, 也兼顾生态环境和经济环境, 形成以产业开发为先导, 以 人为核心，以“产城融合”为建设理念的产业新城[1]。产业新城依据产业优势，在产业发展的 基础上, 对城市功能进行补充, 并提供多种服务项目[2]。在新型城镇化背景下, 产业新城以 人为核心，以产业为基石，是一种产城融合的创新发展模式[3]。

产业新城作为产业园区升级后的产物, 由产业, 人口, 城市组成, 是一种产城融合的结 果。加快产业新城的发展, 有助于促进城市建设, 促进产业的发展。

\section{3. 产业新城发展的困境}

\section{1 有产无城}

在产业园区转型升级下，产业新城应该针对就业人口结构，完善公共服务配套设施，实 现产业升级、服务有保障和人居环境良好，使城市成为产业发展的良好载体[4]。在我国有很 多集聚区、开发区和产业区为了加快当地的经济发展、吸引地方招商引资, 大力地引入工人、 廉价劳动力, 只配套一些最基本的生活设施, 没有建立合理完善的公共服务体系。这些有产 无城的产业新城城市功能滞后, 与城市建设理念相违背, 无法获得进一步发展。产业和城市 是一个相互合作的有机整体, 产和城的协调发展, 使产业依附于城市, 才能跟好地发展产业 新城[5]。

\section{2 有城无产}

产业与城市的融合不是静态的, 而是在各自的演化系统中，不断发展，处于动态平衡中 [6]。产业的发展是产业新城的灵魂, 没有产业支撑的新城就会沦为空城、卧城。我国很多新 城、新区和大学城, 未获得土地开发项目, 在大城市迅速扩张中, 打着新城建设的口号, 建 设了许多有城无产的新城。产业新城的产业发展需要从产业定位、招商引资、运营服务、产 业融资等环节出力, 才能实现产业新城的可持续发展。对于产业新城来说, 仅有产业的简单 迁入是不行的, 必须与城市建设功能相匹配, 发展城市基础设施、公共服务设施以及产业新 城生态环境。

\section{3 产城人不相融}

随着城镇化进程的加快，我国单一的产业新城已经不能适应当前经济发展的形式。产业 是城市的核心，城市是产业的载体，在产业新城发展过程中，既要重视产业的发展，也要重 视人的需求。产业新城做不到产城人融合, 就会失去活力, 实现不了新城的可持续发展。产 业新城的建设关键在于实现居住与就业、产业与城市、人与自然的融合[7]。我国产业新城的 发展首先要考虑的不是产业规模的大小，也不是城市空间的规模大小，而应该是人的需求， 对人的吸引力有多大，只有把人放在第一位，才能真正实现产城人的融合。 


\section{4. 产业新城发展的对策}

\section{1 完善基础设施建设}

产业新城的基础设施是为产业生产和城内居民生活提供公共服务的设施，是用于保证产 业新城社会经济活动正常进行的公共服务系统，是产业新城赖以生存发展的一般物质条件。 基础设施包括交通、供水供电、商业服务、科技服务、文化教育、卫生事业和公共生活服务 设施等。

产城融合发展，需要在就业和生活的需求基础上，建立基本的基础设施，解决职住分离 的问题，建设公共服务体系[8]。

基础设施的建设是产业新城建设发展过程中的基础，是产城融合发展的基本载体，也是 产业新城发展的重要着力点。随着产业新城的不断发展, 运营商需要加大基础设施的建设力 度，以此提升城市承载能力、促进企业的集聚发展，吸引产业人口的流入。

\section{2 调整产业结构}

我国城镇发展和产业发展存在着不协调、不合理的现象，城镇和产业出现分割。产城融 合要促进就业和居住的协调, 住房结构要和就业结构相匹配。产业结构决定城市就业的结构, 调整产业结构有助于促进就业, 完善就业体系, 也是产城融合的关键 [9]。在产业新城建设过 程中, 必须以产城融合理念为导向, 充分发挥产业优势, 优化产业结构, 完善配套产业链, 加快经济发展, 构建与城镇功能相匹配的产业发展体系。推动以产兴城, 以城促产, 实现产 业新城的可持续发展。

\section{3 积极引入人才}

人才是产业新城发展中最活跃的要素, 积极引入人才，需要打破创新人才体制的障碍, 建立科研机构、高校与企业合作的创新人才平台。对重点产业、关键领域、新兴技术人才的 培养要着重加强, 以产业新城的需求为导向, 积极推动人才培养平台, 培养高层次、高水平 的专门人才。加大产业新城科研院所和科技平台的建设, 积极推动创新创业以及产城融合发 展策略，促进产业协同发展和高水平成果的转化，优化人才的结构。对于产业新城的重点行 业, 可以打造知识和服务平台, 引进和培养科技服务机构, 完善人才服务中介机构, 吸引国 内外高层次人才，加快产业新城的建设发展。

\section{5. 结语}

改革开放以来，我国经济不断发展，在新型城镇化背景下，出现了一大批的产业新城， 取得了可喜的成绩。但是我国产业新城依然面临着众多的挑战, 产城不融合是最主要的问题, 产业新城在发展中往往会陷入有产无城或有城无产的局面, 需要产业新城运营商和各级政府 加大基础设施的投入，完善相应的生活服务设施，优化产业结构，以产兴城，以城促产，同 时积极吸引人才，加大对人才的培养力度。

\section{References}

[1] He Jun. Research on PPP mode of industrial new city [D]. Dongbei University of Finance and Economics, 2016.

[2] Wang Ning. Research on the application of PPP mode to industrial new town [D]. Shandong University, 2018.

[3] Jiao Cong. The promotion of the "One Belt, One Road" strategy by the industrial new city model [J]. Business Economics Research, 2016(04): 195-196. 
[4] Xiang Qiaoyu, Lu Bin. Planning and guiding of the modular space construction system of industrial parks under the background of industrial integration[J]. Planner, 2014, 30(06): 17-24.

[5] Li Xuejie. Analysis of the development of the integration of production and city in the process of urbanization [J]. Economist, 2012 (10): 43-44.

[6] Smith K R. Building an Innovation Ecosystem: Process, Culture and Competencies[J]. Industry \& Higher Education, 2006.

[7] Du Baodong. Multidimensional Analysis of the Integration of Production City[J]. Planner, 2014, 30(06): 5-9.

[8] Wang Fangbing, Wu Ruijun. Research on the coordinated development of suburbanization and suburbanization of Shanghai population[J]. Ecology and Economy,2015,31(01):85-90+96.

[9] Li Yugang. Analysis of the development of industrial new city from the perspective of production city integration-Taking Binzhou New Area of Zhangzhou, Fujian Province as an example[J]. China Price, 2017(04): 21-23. 